\title{
IDADE U-Pb DO DIORITO POSSELÂNDIA, HIDROLINA, GOIÁS
}

\author{
HARDY JOST*, MÁRCIO M. PIMENTEL*, REINHARD A. FUCK*, \\ JOSÉ C.M. DANNI* e LARRY HEAMAN**
}

\begin{abstract}
THE U-Pb AGE OF THE POSSELÂNDIA DIORITE, HIDROLINA, GOIÁS. The Posselândia Diorite intrudes Archean granite-greenstone terrains of the region of Hidrolina, Central Goiás, Brazil. U-Pb radiometric determinations in two fractions of zircon crystals from the diorite yield an age of $2,146 \pm 1.6 \mathrm{Ma}$, interpreted as the cristallization age of the intrusion. The lack of deformation in the intrusion demonstrates that condolidation of the granite-greenstone terrains in the Hidrolina-Pilar de Goiás-Crixás area took place before 2,146 Ma.
\end{abstract}

Keywords: Zircon dating, Paleoproterozoic, diorite, granite-greenstone.

RESUMO IDADE U-Pb DO DIORITO POSSELÂNDIA, HIDROLINA, GOIÁS. O Diorito Posselândia intrude terrenos arqueanos do tipo granito-greenstone da região de Hidrolina, Goiás. Determinações isotópicas pelo método U-Pb foram realizadas em duas frações de zircão de amostras do diorito. Após abrasão, os pontos analíticos plotam próximo à concórdia, fornecendo idade de $2.146 \pm 1,6 \mathrm{Ma}$, interpretada como a idade de cristalização da intrusão. A ausência de deformação no Diorito atesta que a sialização e estabilização dos terrenos granito -greenstone da região de Hidrolina-Pilar de Goiás-Crixás estava completa há pelo menos $2.146 \mathrm{Ma}$.

Palovras-chave: Datação de zircões, Paleoproterozóico, diorito, granito-greenstone.

INTRODUÇÃO Os terrenos granito-greenstone, da região central de Goiás, representam possivelmente o segmento mais antigo do chamado Maciço de Goiás, situado entre as faixas de dobramentos proterozóicos da Província Tocantins (Fig. 1). Embora escassos, os dados geocronológicos indicam que esse segmento foi edificado no Arqueano tardio, entre cerca de 3,0 e 2,5 Ga (Tassinari \& Montalvão 1980, Tassinari et al. 1981, Montalvão 1985, Fuck et al 1987,Arnd et al. 1989).

A estabilização final, contudo, parece ter ocorrido mais tarde, a julgar pela idade $\mathrm{Rb}-\mathrm{Sr}$ de 2,1 Ga, obtida no Bloco de Hidrolina por Montalvão (1985). Mais recentemente, o setor esteve envolvido nas deformações compressivas relacionadas ao Ciclo Brasiliano, uma vez que constitui o substrato da nappe de micaxistos do Grupo Araxá (Danni \& Cordeiro 1978, Danni et al 1986). Embora aparentemente pouco afetadas por estas deformações, as suas rochas tiveram o seu sistema isotópico K-Ar parcial ou totalmente rejuvenescido, como se depreende das idades $\mathrm{K}-\mathrm{Ar}$, entre cerca de 500 e $1.000 \mathrm{Ma}$, obtidas por Hasui \& Almeida (1970) e Cordani \& Hasui (1975).

Outros eventos geológicos importantes tiveram lugar na região durante o Proterozóico. Um é representado por intrusões de rochas máficas, na forma de diques e corpos maiores, como é o caso do Diorito Posselândia. Suas rochas são intrusivas nas sequências supracrustais do Greenstone Belt de Pilar de Goiás-Hidrolina e nos gnaisses tonalíticos e granodioríticos expostos no Bloco de Hidrolina (Danni et al. 1986).

Por representarem um importante marco na evolução geológica regional dos terrenos granito-greenstone de Goiás, as rochas do Diorito Posselândia foram estudadas com maior detalhe, incluindo a determinação de sua idade pelo método U-Pb em zircão.

GEOLOGIA REGIONAL A região de Crixás compreende (Fig. 1) três faixas vulcano-sedimentares do tipo

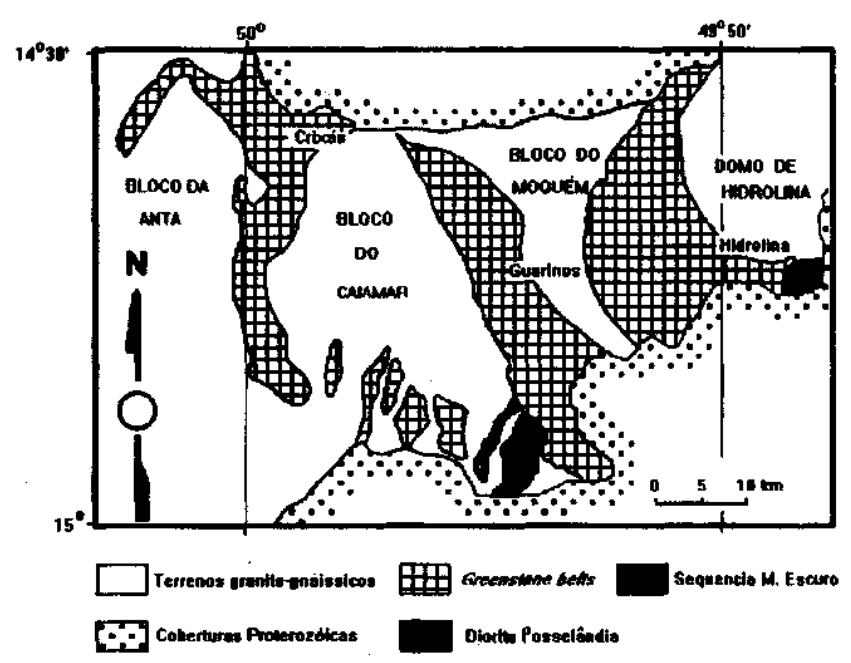

Figura 1 - Localização e esboço geológico da região de terrenos do tipo granito-greenstone belt, de Crixás, Goiás, mostrando a localização do Diorito Posselândia (preto). Blocos com denominação consistem de tonalitos e granodioritos. Areas com denominação consistem de tonalitos e granodioritos

Figure 1 - Location and geologic outline of the granite-greenstone terrains of the Crixás region, Central Brazil, showing the location of the Posselândia Diorite (black). Named blocks are made up of tonalite and granodiorite

greenstone belt denominadas de Crixás, Guarinos e Pilar de Goiás. Elas são confinadas por complexos de gnaisses denominados de Anta, Caiamar, Moquém e Hidrolina. Os greenstone belts dispõem-se em faixas subparalelas, alongadas

\footnotetext{
* Instituto de Geociências, Universidade de Brasília, 70910-970, Brasília, DF, Brasil

** Royal Ontario Museum, Ontario, Canada
} 
aproximadamente segundo a direção norte-sul, com cerca de $35 \mathrm{~km}$ de extensão e $7 \mathrm{~km}$ de largura.

Idades radiométricas forneceram valores mínimos de 2,1 Ga para os gnaisses tonalíticos de parte do Bloco da Anta, enquanto gnaisses granodioríticos do Bloco Caiamar forneceram, pelo método $\mathrm{Pb}-\mathrm{Pb} 2,48 \pm 180 \mathrm{Ga}$ (Tassinari \& Montalvão 1980, Tassinari et al 1981, Montalvão 1985). Datações $\mathrm{Sm}-\mathrm{Nd}$ e $\mathrm{Pb}-\mathrm{Pb}$, em komatiitos do greenstone belt de Crixás, indicaram idade em tomo de 2,8 Ga (Arndt et al 1989).

Aproximadamente $70 \%$ da região consiste de granitóides que envolvem, e em parte intrudem, os cinturões vulcanosedimentares, e cuja composição varia de diorítica a granítica. $\mathrm{O}$ contato entre os diversos corpos de granitóides e as rochas supracrustais varia de um corpo a outro, mas em geral o contato é intrusivo e, por conseguinte, brusco, eventualmente com auréola de metamorfismo de contato, ou, alternativamente, tectônico, comumente caracterizado por zonas de cisalhamento marcadas por milonitos.

De acordo com a estrutura e composição, os granitóides da região podem ser agrupados em cinco categorias: (i) domos tonalíticos com incipiente deformação regional, como nos Complexos da Anta e Caiamar, (ii) domos granodioríticos, em geral com conspícua foliação divergente a partir do núcleo e com intensidade que diminui da borda para o centro dos corpos, como exemplifica o núcleo do Domo de Hidrolina, (iii) blocos de gnaisses polifásicos tonalíticos até graníticos, como no Bloco do Moquém, (iv) pequenos corpos trondhjemíticos que ocorrem como intrusões tabulares no interior de zonas de cisalhamento que cortam as supracrustais arqueanas, ou como stocks naquelas, em geral com estreitas auréolas de metamorfismo de contato, como o núcleo do Domo de Guarinos, e (v) stocks circulares a ligeiramente elípticos, ora de granitos ora de dioritos, intrudidos no interior de possantes zonas de cisalhamento que recortam a estrutura arqueana regional, como o Diorito Posselândia, e pequenos corpos de granitos potássicos, os quais intrudem a Zona de Cisalhamento Taquaruçú (Fig. 1), também com efeitos de metamorfismo de contato, particularmente em supracrustais.

As rochas supracrustais da região compreendem dois grupos, isto é, associações vulcano-sedimentares do tipo greenstone belt, e coberturas do Proterozóico. As primeiras, em geral emolduradas por complexos granito-gnáissicos, genericamente compreendem komatiitos basais, que dão lugar a derrames de basaltos toleííticos, os quais estão recobertos por metassedimentos diversos. As rochas vulcânicas estão, comumente, intercaladas de chert e formações ferríferas e manganesíferas. Estruturalmente, as sequências vulcano-sedimentares mostram cinco fases de deformação, dentre as quais a mais proeminente é responsável pela orientação aproximadamente norte-sul e mergulho moderado a suave para oeste-sudoeste das supracrustais.

As coberturas do Proterozóico estão representadas por rochas metassedimentares que vêm sendo correlacionadas ao Grupo Araxá (Danni et al 1986). Na área estudada, os metassedimentos consistem de um quartzito basal, sotoposto a uma associação de filitos com proporções variadas de carbonato, que, para o topo, grada para uma sequência de quartzo-muscovita xistos, não raro com granada. $\mathrm{O}$ pacote representa uma sucessão de sedimentos depositados em plataforma rasa.

As rochas metassedimentares do Proterozóico recobrem indistintamente todos os tipos de granitóides e truncam a estruturação dos greenstone belts. O contato do Grupo Araxá com o conjunto de rochas do bloco precedente é uma zona de milonitos, com quem se associam dobras recumbentes, dobras inversas e escamas tectônicas, todas desenvolvidas durante um importante evento de tectônica tangencial do Neoproterozóico.
DIORITO POSSELÂNDIA O Diorito Posselândia localiza-se entre Hidrolina e a vila Posselândia, a nordeste da primeira, no Município de Hidrolina, Goiás (Fig. 2). O acesso à região é feito a partir de Anápolis para norte por cerca de $100 \mathrm{~km}$, pela Rodovia Belém-Brasília, até São Luiz do Norte. A partir dessa localidade, segue-se por estrada pavimentada para Hidrolina. Aproximadamente $3 \mathrm{~km}$ antes de Hidrolina, toma-se uma estrada vicinal para norte, em direção à vila Posselândia, alcançando-se os primeiros afloramentos do Diorito a $7 \mathrm{~km}$ do entroncamento.

Apenas a porção noroeste do Diorito Posselândia aflora. Esta tem uma forma aproximadamente retangular (Fig. 2), com cerca de $30 \mathrm{~km}^{2}$. A forma e extensão do corpo inteiro são desconhecidas, em razão da cobertura de metassedimentos do Grupo Araxá a sul e leste. A norte e noroeste, a intrusão limita-se com gnaisses granodioríticos do núcleo do Domo de Hidrolina. A oeste, o contato é feito com rochas metavulcânicas máficas e ultramáficas ao greenstone belt de, Pilar de Goiás.

O Diorito Posselândia é uma rocha de cor cinza-escura, granulação média a fina, em geral isótropa, com foliação local magmática. Xenólitos de rochas básicas e formações ferríferas do greenstone belt e gnaisses são comuns. Localmente, ocorrem também autólitos.

Uma incipiente foliação protomilonítica pode ocorrer ao longo dos limites sul e leste da intrusão, por influência do transporte tectônico do Grupo Araxá na área. Contudo, esta foliação é de extensão e expressão limitada às proximidades do contato. Na porção norte, ocorrem, por vezes, corpos pegmatóides com até dezenas de metros de comprimento e possança métrica, constituídos por quartzo e microclínio.

Ao microcópio, a textura é granular hipidiomorfa média. Os constituintes maiores compreendem diopsídio, hiperstênio e plagioclásio (oligoclásio-andesina), com quartzo, biotita, apatita, titanita e opacos, eventualmente epídoto, como acessórios. A horablenda, quando presente, é uralítica sobre os piroxênios.

A composição química de três amostras do Diorito consta da tabela I. A posição geográfica das amostras analisadas consta do mapa da figura 2. A amostra "A" provém da porção interna da intrusão, enquanto a amostra " $\mathrm{C}$ " situa-se junto à borda, com a "B" em posição intermediária. A comparação entre a composição da amostra "A" e as demais sugere que a intrusão é mais ácida no núcleo que nas bordas.

\section{Tabela I - Composição química de amostras do Diorito Posselândia}

Table I - Chemical composition of samples from the Posselândia Diorite

\begin{tabular}{cccc} 
& \multicolumn{3}{c}{ AMOSTRAS } \\
\cline { 2 - 4 } & \multicolumn{1}{c}{$\mathrm{A}$} & $\mathrm{B}$ & $\mathrm{C}$ \\
\hline $\mathrm{SiO}_{2}$ & 58,13 & 54,43 & 54,16 \\
$\mathrm{Al}_{2} \mathrm{O}_{3}$ & 16,47 & 17,22 & 17,45 \\
$\mathrm{Fe}_{2} \mathrm{O}_{3}$ & 0.74 & 1,55 & 1,50 \\
$\mathrm{FeO}$ & 4,95 & 5,66 & 5,71 \\
$\mathrm{CaO}$ & 6,40 & 7,69 & 7,74 \\
$\mathrm{MgO}$ & 4,97 & 6,00 & 6,02 \\
$\mathrm{Na} 2$ & 4,13 & 3,85 & 3,80 \\
$\mathrm{~K}_{2} \mathrm{O}$ & 1,53 & 1,00 & 0,99 \\
$\mathrm{MnO}$ & 0,11 & 0,14 & 0,13 \\
$\mathrm{P}_{2} \mathrm{O}_{5}$ & 0,24 & 0,28 & 0,30 \\
$\mathrm{TiO}_{2}$ & 1,02 & 1,02 & 1,06 \\
$\mathbf{P . F}$ & 0,44 & 0,38 & 0,39 \\
\hline
\end{tabular}




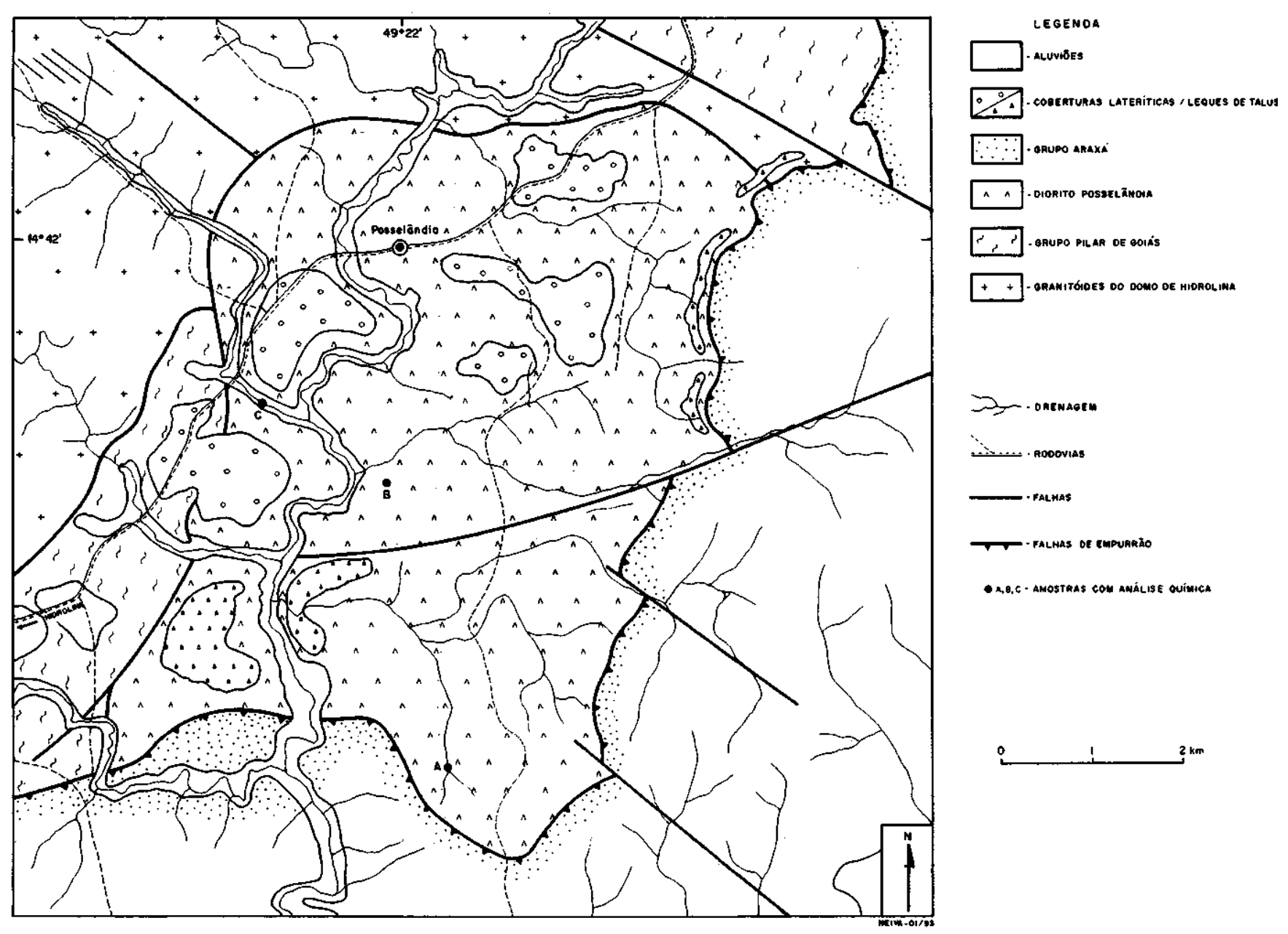

Figura 2 - Mapa geológico da porção exposta do Diorito Posselândia, greenstone belt de Pilar de Goiás Figure 2 - Geologic map of the exposed portion of the Posselândia Diorite, Pilar de Goiás greenstone belt, Goiás

PROCEDIMENTO ANALÍTICO Os cristais de zircão analisados provém de amostra de diorito coletada nas proximidades do povoado de Posselândia, aproximadamente no centro do corpo intrusivo. A fração de minerais pesados foi obtida por moagem e bateamento de cerca de $20 \mathrm{~kg}$ de rocha, nos laboratórios da Companhia Vale do Rio Doce, Belo Horizonte. Os minerais pesados foram processados por peneiramento, separação magnética em separador isodinâmico Frantz e por líquidos pesados (bromofórmio e iodeto de metilênio) no laboratório de geocronologia do Royal Ontario Museum (ROM), Toronto.

Apenas uma população de zircão foi reconhecida na amostra. Os grãos foram separados à mão, em álcool etílico filtrado, com auxílio de lupa binocular e foram abundantes e de excelente qualidade. São caracteristicamente prismáticos, euédricos, de cor rosa, transparentes, não-magnéticos, destituídos de alteração e fraturas e sem feições visíveis de zonação ou sobrecrescimento.

Os grãos selecionados foram polidos em presença de pirita, segundo a técnica de Krogh (1982), divididos em duas frações, lavados com $\mathrm{HNO}_{3} 4 \mathrm{~N}$ a quente, e, após, enxaguados respectivamente em água destilada e acetona. Em seguida, foram pesados e dissolvidos em uma mistura (15:1) de $\mathrm{HF}$ e $\mathrm{HNO}_{3} 8 \mathrm{~N}$, em bombas de dissolução de Teflon, a $220^{\circ} \mathrm{C}$. Nesse estágio, foi adicionado um traçador isotópico (spike) misto ${ }^{205} \mathrm{~Pb}-{ }^{235} \mathrm{U}$ (Krogh \& Davis 1975). Dissolução e extração química de $\mathrm{U}$ e $\mathrm{Pb}$ seguiram os procedimentos gerais propostos por Krogh (1973). Pb e U foram depositados como fosfates com sílica-gel sobre um mesmo filamento de rênio degaseificado, e as determinações isotópicas foram realizadas em espectrômetro de massa VG-354 no ROM. Detalhes dos procedimentos podem ser obtidos em Krogh \& Turek (1982) e Davis et al (1982).

Os dados isotópicos foram corrigidos para valores de fracionamento de $0,1 \%$ por unidade de massa atómica. Ao tempo das análises, os brancos de $\mathrm{U}$ e $\mathrm{Pb}$ no laboratório foram de 1 e $2 \mathrm{pg}$, respectivamente. As composições para a correção do $\mathrm{Pb}$ comum inicial foram derivadas das curvas de crescimento propostas por Stacey \& Kramers (1975). Para a correção do branco, foi utilizada a relação ${ }^{208} \mathrm{~Pb}:{ }^{207} \mathrm{~Pb}:{ }^{206} \mathrm{~Pb}:{ }^{204} \mathrm{~Pb}=37,6: 15,6: 18,3: 1,0$. A linha de regressão foi computada segundo o método de Davis (1982), sendo os erros na idade apresentados ao nível de $95 \%$ de confiança. As constantes de desintegração e a composição isotópica do urânio são as recomendadas por Steiger \& Jäger (1977).

RESULTADOS Os dados U-Pb determinados para o Diorito Posselândia estão listados na tabela II. Como mencionado, a única população de zircão encontrada na amostra foi dividida, para fins de análise, em duas frações. Os pontos reprentativos dos dados analíticos plotam próximos à curva concórdia (Fig. 3), com discordâncias de 0,3 e $0,7 \%$, respectivamente. $\mathrm{O}$ intercepto superior da regressão calculada fornece valor de $2.146 \pm 1,6 \mathrm{Ma}$ (Fig. 3), interpretado como a idade de cristalização do Diorito. 
Tabela II - Resultados radiométricos do Diorito Posselândia

Table II - Radiometric results of the Posselândia Diorite

\begin{tabular}{|c|c|c|c|c|c|c|c|c|c|c|c|}
\hline Amostra & $\begin{array}{l}\text { Peso } \\
\text { (mg) }\end{array}$ & $\begin{array}{c}\mathrm{U} \\
(\mathrm{ppm})\end{array}$ & $\begin{array}{l}\text { Po total } \\
\text { (ppm) }\end{array}$ & $\begin{array}{l}\mathrm{Pb} \text { rad } \\
(\mathrm{ppm})\end{array}$ & $\frac{\sqrt{207} \overline{P b}}{{ }^{204} \mathrm{~Pb}}$ & $\frac{206 \mathrm{Fb}}{{ }^{206} \mathrm{U}}$ & $\frac{{ }^{207} \mathrm{~Pb}}{{ }^{235} \mathrm{U}}$ & $\frac{207 \mathrm{~Pb}}{{ }^{206} \mathrm{~Pb}}$ & $\begin{array}{c}t 1 \\
206 / 238\end{array}$ & $\begin{array}{c}t 2 \\
207 / 235\end{array}$ & $\begin{array}{c}\mathrm{t} 3 \\
207 / 206\end{array}$ \\
\hline G.88.33.1 & 63 & 121,1 & 53,17 & 53,15 & 22.713 & $0,3936(15)$ & $7,247(26)$ & $0,1335(1)$ & 2.140 & 2142 & 2145 \\
\hline G.88.33.2 & 516 & 111,2 & 48,71 & 48,68 & 10.267 & $0,3918(9)$ & $7,208(16)$ & $0,1334(0)$ & 2131 & 2138 & 2144 \\
\hline
\end{tabular}

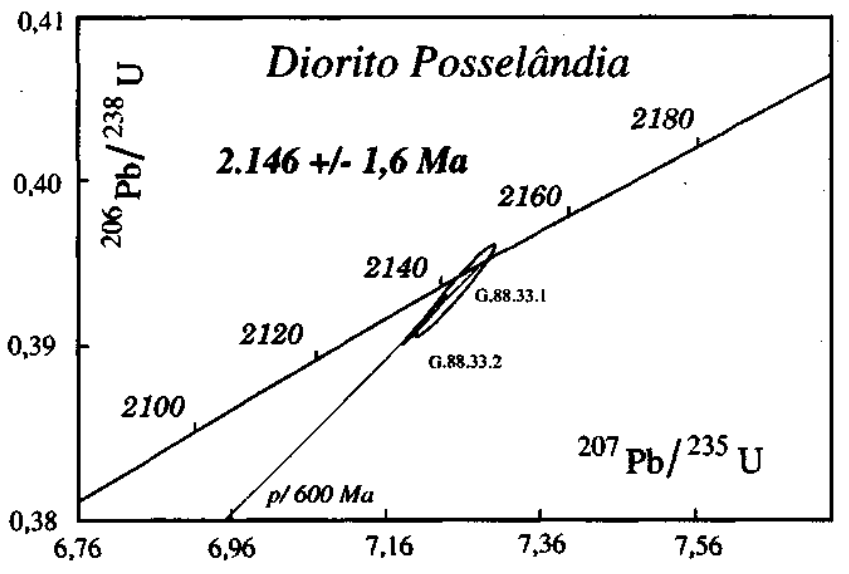

Figura 3 - Diagrama concórdia para o Diorito Posselândia Figure 3 - Concordia diagram of the Posselândia Diorite

$\mathrm{O}$ intercepto inferior, com cerca de $600 \mathrm{Ma}$, tem significado desconhecido, podendo, entretanto, representar perda de chumbo relacionada com o evento de cavalgamento do Grupo Araxá sobre os terrenos gramio-greenstone durante o Ciclo Brasiliano na região.
CONCLUSÃO Considerando que o Diorito Posselândia não está deformado, exceto junto ao contato com as rochas supracrustais alóctones do Grupo Araxá, relacionadas com a orogênese brasiliana, sua intrusão deu-se após a consolidação dos terrenos granito-greenstone, do setor central de Goiás. A intrusão sinaliza a presença de uma litosfera continental consolidada, cuja ruptura permitiu o acesso de líquidos magmáticos mantélicos, que se alojaram e cristalizaram em zonas distensionais. A idade U-Pb de $2.146 \pm 1,6 \mathrm{Ma}$, obtida em zircões da intrusão diorítica, assinala que a crosta continental da região foi afetada por importante processo distensional no Paleoproterozóico, e, por extensão, estabelece a idade mínima da sialização e estabilização dos terrenos granito-greenstone de Goiás central.

Agradecimentos À Canadian International Development Agency (CIDA), pelo apoio financeiro para a obtenção dos dados isotópicos. Aos pesquisadores e técnicos do Royal Ontario Museum, onde as análises U-Pb foram realizadas. Ao Conselho Nacional de Desenvolvimento Científico e Tecnológico $(\mathrm{CNPq})$ e ao Programa de Apoio ao Desenvolvimento Científico e Tecnológico (PADCT), pelo apoio financeiro mediante Bolsas de Pesquisador e apoio de campo.

\section{REFERÊNCIAS BIBLIOGRÁFICAS}

ARNDT, N.T.; TEIXEIRA, N.A.; WHITE, W.M. 1989. Bizarre geochemistry of komatiites from the Crixás Greenstone Belt, Brazil. Contrib. Mineral. Petrol, 101:187-197.

CORDANI, U. G. \& HASUI, Y. 1975. Comentários sobre os dados geocronológicos disponíveis para a Folha Goiás. In: Carta Geológica do Brasil ao Milionésimo. Folha Goiás (SD-22). Brasilia, DNPM, SGM, p. 85-98

DANNI, J.C.M.; JOST, H.; WINGE, M.; ANDRADE, G.F. 1986. Aspectos da evolucão dos terrenos granitos-greenstone: exemplo da região de Hidrolina. In: CONGR. BRAS. GEOL., 32. Goiânia, 1986. Anais... Goiânia, SBG. v. 2, p. 570-584.

DAVIS, S.W. 1982. Optimum linear regression and error estimation applied to U-Pb data. Can. J. Earth Sci., 19:2141-2149.

DAVIS, S.W.; BLACKBURN, C.E. KROGH, T.E. 1982. Zircon U-Pb ages from the Wabigoon-Maniton lakes region, Wabigoon Subprovince, northwest Ontario. Can J. Earth Sci., 19:258-266.

FUCK, R.A.; PIMENTEL, M.M.; BOTELHO, N.F. 1987. Granitoid rocks in west-central Brazil: a review. In: INTERN. SYMP. GRANITES AND ASSOC MINERALIZATION. Salvador, 1987. Extended Abstracts... Salvador, SGRM. p. 53-59.

HASUI, Y. \& ALMEIDA, F.F.M. 1970. Geocronologia do Centro-Oeste brasileiro. Bol. Soe. Bras. Geol, 19(1):5-26.

KROGH, T.E. 1973. A low-contamination method for hydrothermal decomposition of zircon and extraction of $\mathrm{U}$ and $\mathrm{Pb}$ for isotopic age determinations. Geochim. Cosmochim. Acta., 37:485-494.

KROGH, T.E. 1982. Improved accuracy of U-Pb ages by creation of more concordant fractions using an air abrasion technique. Geochim. Cosmochim. Acta, 46:637-649.
KROGH, T.E. \& DAVIS, G.L. 1975. The production and preparation of ${ }^{205} \mathrm{~Pb}$ for use as a tracer for isotope dilution analysis. Carnegie Inst. Washington, Yearb., 74:416-417.

MQNTALVAO, R.M.G. 1985. Evolucão Geotectônica dos Terrenos Granitóides - Greenstone Belts de Crixás, Guarinos, Pilar de Goiás - Hidrolina (Goiás). São Paulo. 372 p. (Tese de Doutoramento, IG-USP).

STACEY, J.S. \& KRAMERS, J.S. 1975. Approximation of terrestrial lead isotope evolution by a two-stage model. Earth Planet. Sci. Lett., 6:15-25.

STEIGER, R.H. \& JÀGER, E. 1977. Subcomission on geochronology convention on the use of decay constants in geo- and cosmochronology. Earth Planet. Sci. Lett., 36:359-362.

TASSINARI, C.G.C. \& MONTALVAO, R.M.G 1981. Estudo geocronológico do Greenstone Belt de Crixás. In: CONGR. BRAS. GEOL., 32. Camboriú, 1980. Anais... Camboriú, SBG. v. 5, p. $2752-2759$.

TASSINARI, C.C.G.; SIGA Jr., O. \& TEIXEIRA. W. 1981. Panorama geocronológico do centro-oeste brasileiro: solução, problemática e sugestões. In: SIMP. GEOL. CENTRO-OESTE, 1. Goiânia, 1981. Atas... Goiânia, SBG-NCO/NBR. p. 93-116.

MANUSCRITO A806 Recebido em 22 de novembro de 1993 Revisão do autor em 13 de julho de 1993 Revisão aceita em 23 de julho de 1994 